\title{
Asthma clinical trials of American Lung Association/Asthma Clinical Research Centers (ALA-ACRC): what have we learned in 12 years?
}

\author{
Kaharu Sumino • Janet T. Holbrook • Robert A. Wise • \\ Linda Rogers
}

Published online: 18 September 2012

(C) Springer Science+Business Media, LLC 2012

\begin{abstract}
The American Lung Association Asthma Clinical Research Centers (ALA-ACRC) is a research network focused on performing clinical trials that directly affect medical care for adults and children with asthma. The group of eighteen clinical research centers and a data-coordinating center perform studies supported by the American Lung Association, the National Institute of Health/National Heart Lung and Blood Institute (NIH/NHLBI), and partnership with industry. The network has completed and published eight clinical trials (seven randomized control trials and one validation study of a diagnostic tool), numerous ancillary studies, and has four ongoing trials at the time of publication of this review. The network's trials have focused on areas such as the relative merits of different adjunctive treatments for asthma not controlled on inhaled corticosteroids (ICS) alone, the effect of treatment of comorbid diseases on asthma care, and studies evaluating techniques used in the conduct of clinical trials of treatments for asthma. This review will describe the accomplishments of our network to date and the effect of those accomplishments on asthma care.
\end{abstract}

\footnotetext{
K. Sumino $(\triangle)$

Washington University School of Medicine,

660 Euclid Avenue, Campus box 8052, Saint Louis,

MO 63110, USA

e-mail: ksumino@dom.wustl.edu

J. T. Holbrook

Bloomberg School of Public Health, Johns Hopkins University,

Baltimore, MD, USA
}

\section{R. A. Wise}

Johns Hopkins University School of Medicine,

Baltimore, MD, USA

L. Rogers

New York University School of Medicine,

New York, NY, USA
Keywords Asthma Clinical Trials · American Lung Association · Asthma Clinical Research Centers . Treatment $\cdot$ Diagnosis

\section{Introduction: American Lung Association Asthma Clinical Research Center centers (ALA-ACRC)}

The Asthma Clinical Research Center (ACRC), sponsored by the American Lung Association (ALA), is one of the largest asthma clinical research networks in the United States. It was established in 1999 by the ALA to promote randomized clinical trials on adult and pediatric asthma patients that would directly affect patient care and asthma treatment. The ACRC consists of a network of clinical centers (currently 18 centers across the nation), a data-coordinating center, and a chairman (current and former centers are listed in the "Acknowledgements"). The network has successfully completed eight clinical trials (seven randomized clinical trials and one validation study for a diagnostic tool) on asthma $[1,2,3 \cdot, 4,5,6 \bullet \bullet, 7,8 \bullet \cdot$ (Table 1) that have added significantly to the evidence base for asthma management and for the conduct of asthma studies. Several studies are regarded as being among the landmark studies in asthma management and are described in detail below. The ALA provides funding for the infrastructure of the network via grants to the centers. Funding and support for individual protocols comes from the ALA, NIH/NHLBI grants, and industry support including grant funding and provision of drugs for studies. In this review, we describe each of the eight studies and their effect on the treatment and management of asthma and clinical study design. We will also briefly describe current ongoing and upcoming trials. 
Table 1 Characteristics of participants enrolled in ALA-ACRC Trials (2000-2011)

\begin{tabular}{|c|c|c|c|c|c|c|c|c|}
\hline $\begin{array}{l}\text { Trial } \\
\text { Year(s) conducted }\end{array}$ & $\begin{array}{l}\text { SIIVA } \\
2000\end{array}$ & $\begin{array}{l}\text { LODO } \\
2002-2003\end{array}$ & $\begin{array}{l}\text { LOCCS } \\
2003-2005\end{array}$ & $\begin{array}{l}\text { TAPE } \\
2003-2005\end{array}$ & $\begin{array}{l}\text { SIRNA } \\
2005-2006\end{array}$ & $\begin{array}{l}\text { SARA } \\
\text { 2004-2008 }\end{array}$ & $\begin{array}{l}\text { MeCIS } \\
2009-2010\end{array}$ & $\begin{array}{l}\text { SARCA } \\
2007-2011\end{array}$ \\
\hline$N$ & 2031 & 489 & 500 & 601 & 64 & 402 & 219 & 306 \\
\hline Age (mean years) & 30 & 40 & 31 & 38 & 35 & 42 & 36 & 11 \\
\hline Participants $<18$ years $(\%)$ & 37 & 5 & 20 & 5 & 0 & 0 & 9 & 100 \\
\hline Male $(\%)$ & 38 & 26 & 40 & 28 & 28 & 32 & 36 & 61 \\
\hline \multicolumn{9}{|l|}{ Race or ethnic group (\%) } \\
\hline White & 65 & 61 & 61 & 58 & 75 & 51 & 66 & 33 \\
\hline Black & 25 & 29 & 27 & 32 & 20 & 38 & 22 & 50 \\
\hline Hispanic & 6 & 8 & 8 & 7 & 5 & 9 & 8 & 11 \\
\hline Other & 4 & 2 & 3 & 3 & 0 & 2 & 4 & 5 \\
\hline \multicolumn{9}{|l|}{ Asthma characteristics (\%) } \\
\hline $\begin{array}{l}\geq 1 \text { Urgent visit for asthma in } \\
\text { previous year }\end{array}$ & 48 & 47 & 34 & 28 & 26 & 60 & 29 & 73 \\
\hline $\begin{array}{l}\geq 1 \text { Course oral corticosteroids } \\
\text { in previous year }\end{array}$ & 48 & 44 & 29 & 26 & 13 & 50 & 30 & 67 \\
\hline Daily use of inhaled corticosteroids & 54 & 76 & 26 & 54 & 17 & 100 & 23 & 44 \\
\hline \multicolumn{9}{|l|}{ Asthma characteristics (mean) } \\
\hline Asthma control score ${ }^{\mathrm{a}}$ & $\mathrm{NC}$ & $\mathrm{NC}$ & 1.69 & 1.77 & 1.42 & 1.86 & 1.09 & 1.19 \\
\hline ASUI score ${ }^{b}$ & 0.83 & 0.68 & NS & NS & $\mathrm{NC}$ & 0.76 & $\mathrm{NC}$ & 0.82 \\
\hline $\mathrm{FEV}_{1} \%$ pred pre-BD & $91^{\mathrm{c}}$ & 79 & 86 & 87 & 86 & 77 & 91 & 92 \\
\hline FVC \% pred pre-BD & $95^{\mathrm{c}}$ & 107 & 96 & 95 & 92 & 87 & 97 & 101 \\
\hline
\end{tabular}

${ }^{a}$ Lower value indicates less severe asthma, range for ACS is 0 to 7

${ }^{\mathrm{b}}$ Higher value indicates less severe asthma, range for ASUI is 0 to 1

${ }^{\mathrm{c}}$ Collected on $1010\left(\mathrm{FEV}_{1}\right)$ and 1007 (FVC) participants

Table key: $S D$ standard deviation; $F E V_{l}$ forced expiratory volume in 1 second; $B D$ bronchodilator; $F V C$ forced vital capacity; $N C$ not collected; $N S$ not collected at enrollment visit

\section{Direct asthma treatment trials (LOCCS, LODO)}

Does adding low-dose theophylline or montelukast provide better asthma control for patients with poorly controlled asthma?

\section{Effectiveness of low-dose theophylline as add-on therapy in treatment of asthma (LODO)}

LODO examined whether theophylline, a relatively inexpensive asthma medicine, can be used safely and effectively at lower doses than typically prescribed. Add-on therapy with theophylline in addition to baseline asthma treatment was compared with both an active (montelukast) and placebo control for a period of six months. The study enrolled 489 adolescents and adults with poorly controlled asthma over an 11-month period in 2002. Neither montelukast nor low-dose theophylline reduced the incidence of episodes of poor asthma control in patients with poorly controlled asthma despite improved lung function compared with the placebo group [2]. For patients not using inhaled corticosteroids at baseline, low-dose theophylline improved asthma symptom control more than montelukast or placebo, reduced the asthma exacerbation rate to $1.8(95 \% \mathrm{CI}$
$1.1-3.0, p=0.002$ ), and was not associated with the side effects and toxicity seen at higher doses. This finding suggested that low-dose theophylline might be a safe, convenient (once a day), and low-cost alternative asthma treatment that could result in large potential cost savings to the healthcare system. Other findings from LODO show that significant sleep quality disturbances were not uncommon among the asthma patients studied and were associated with daytime sleepiness [9]. Ancillary studies confirmed the associations between known leukotriene pathway polymorphisms and response to montelukast, and also identified novel genetic associations $[10,11]$.

Can patients with mild asthma well controlled on low-dose ICS (fluticasone propionate $100 \mu \mathrm{g}$ twice daily) be switched to either montelukast 5 or $10 \mathrm{mg}$ once daily, fluticasone/ salmeterol $100 \mu \mathrm{g} / 50 \mu \mathrm{g}$ once daily and maintain similar levels of asthma control?

The leukotriene modifier or corticosteroids or corticosteroid-salmeterol trial (LOCCS)

LOCCS enrolled 500 participants with mild asthma to determine the best step-down therapy for those who are well- 
controlled on low-dose ICS. The trial was conducted from 2003 to 2005. The study demonstrated that fluticasone $100 \mu \mathrm{g}$ twice daily or fluticasone/salmeterol $100 \mu \mathrm{g} / 50 \mu \mathrm{g}$ once daily provided better asthma control than montelukast alone, as determined by reduced treatment failures, fewer nocturnal awakenings, better lung function, and better asthma control questionnaire (ACQ) scores (Fig. 1). Other measures of asthma control did not differ between treatment groups including the asthma symptom utility index, adult asthma quality of life, and percentage of symptom-free days. The study concluded that patients with asthma that are well controlled with the use of twice-daily inhaled fluticasone could be switched to once-daily fluticasone plus salmeterol without increased incidence of treatment failure. Switching to montelukast resulted in a greater incidence of treatment failure and reduced asthma control; however, patients taking montelukast remained asthma-symptom-free on $79 \%$ of days, suggesting that monotherapy with montelukast may be a choice for those patient who do not wish to be treated with daily ICS $[3 \bullet]$.

\section{Studies that affect diagnosis and/or how we conduct clinical trials (SIRNA, TAPE, MECIS)}

ACRC has not only conducted studies on asthma treatment, but also on the diagnosis of comorbid sinonasal disease in patients with asthma, the effect of drug presentation, and use

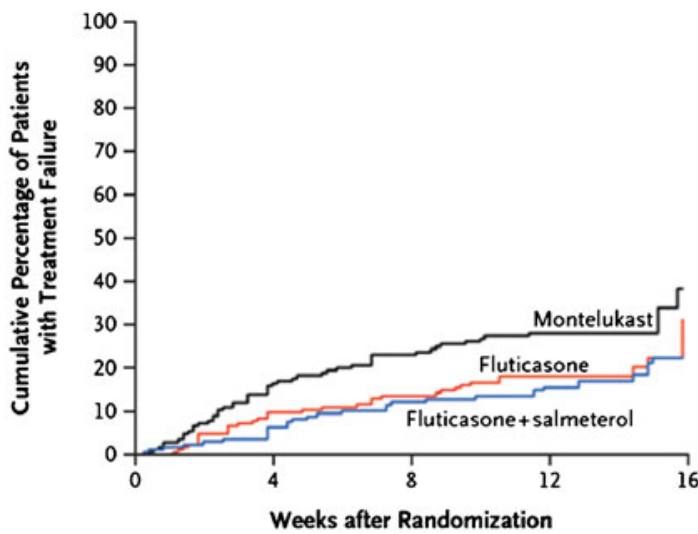

\section{No. at Risk}

Montelukast

Fluticasone

Fluticasone+

salmeterol

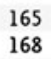

168

162

\section{1}

149

152
126

140

134

\section{8 \\ 131}

131

Fig. 1 Kaplan-Meier estimates of cumulative percentages of patients with treatment failure in LOCCS study. Fluticasone $100 \mu \mathrm{g}$ twice daily or fluticasone/salmeterol $100 \mu \mathrm{g} / 50 \mu \mathrm{g}$ once daily provided better asthma control than Montelukast alone, as determined by reduced treatment failures [3•]. From The New England Journal of Medicine, The American Lung Association Asthma Clinical Research Centers, Randomized Comparison of Strategies for Reducing Treatment in Mild Persistent Asthma, Volume 356, Number 20, 2027-39. Copyright (2007) Massachusetts Medical Society. Reprinted with permission

of placebos on asthma outcomes, and the diagnosis of asthma using challenge testing.

Development of a questionnaire to diagnosis chronic sinonasal disease in patients with asthma

\section{Sinusitis and rhinitis in asthma study (SIRNA)}

Rhinitis is found in approximately $25 \%$ of the general population. Rhinitis is even more common in patients with asthma, with a prevalence reported to be as high as $90 \%$ $[12,13]$. Sinusitis is also common in those with asthma, reported in approximately $30-40 \%$ of asthma patients, and has been linked to poor asthma control [14-16]. Guidelines have recommended screening for and treatment of sinonasal disease to improve asthma control, however neither the optimum manner of screening nor the benefit of treatment of patients identified by screening has been clearly demonstrated in a clinical trial. The objective of the SIRNA study was to develop a screening tool to identify rhinitis and/or sinusitis in asthmatics that could be used in clinical studies. In the SIRNA study, 59 subjects with asthma underwent extensive evaluation including questionnaires, nasal endoscopy, and CT scanning to assess presence or absence of sinonasal disease [4]. An expert panel diagnosed sinonasal disease using the Delphi method to achieve consensus [17]. Using expert panel diagnosis as the recommended standard, a six-item questionnaire based on frequency of nasal symptoms was developed (minimum specificity, 0.90). In a second validation set, the sensitivity of the sinonasal questionnaire (SNQ) was $0.90(95 \%$ CI $0.77-0.97)$, the specificity was 0.94 (95\% CI $0.71-1.00)$, and the area under the receiver operating characteristic curve was $0.97(95 \%$ CI 0.93-1.0). Interestingly, this study also found that sinus CT scans and nasal endoscopy had poor sensitivity for diagnosis of chronic sinonasal disease. Screening with a tool such as the SNQ could potentially minimize the need for invasive endoscopic examinations, and the radiation exposure and expense of CT scans, for many patients with asthma. Moreover, this study became the basis for a clinical trial on the affect of treatment of sinonasal disease on asthma control (STAN) that will be described below.

Can the response to placebo or an active treatment can be enhanced by messages that increase expectation of the benefit?

\section{The trial of asthma patient education (TAPE)}

TAPE was a unique ACRC trial that evaluated the effect of patient education on the response to a placebo or an active treatment. The trial was a modified factorial design, with five treatment groups. Six-hundred and one patients with 
mildly symptomatic asthma were randomized to receive montelukast or placebo or usual care. Patients randomized to montelukast or placebo were also randomized to receive either an enhanced presentation of the study treatment or a neutral presentation. The enhanced presentation was designed to increase expectancy of therapeutic benefit. The modified factorial design enabled us to compare the effects of the enhanced presentation independently in the montelukast and placebo group, to see if increasing expectancy was able to improve outcomes equally in both groups. The fifth group, usual care, was compared with the placebo group receiving the neutral presentation to estimate the placebo effect. Peak flow and other lung function measures were similar in those assigned to enhanced message or neutral message groups for both montelukast and placebo. Asthma control for placebo-treated patients who received enhanced message was better than for those who received neutral message, but no difference was seen between those receiving enhanced vs. neutral message for montelukast-treated patients. These results suggest that enhancing expectations about the effectiveness of a drug may augment the placebo effect on subjective measures of asthma control, but not lung function. Furthermore, "nocebo" effects were observed on side effects. More patients reported headache in the placebo group after receiving information about possible side effects than those on placebo who did not receive similar information [5].

What is the diagnostic performance of the methacholine challenge test for patients with physician-diagnosed asthma on controller therapy?

\section{Methacholine bronchoprovocation -effect of high-potency inhaled corticosteroids in asthma (MECIS)}

MECIS was a study that evaluated the diagnostic performance of the methacholine challenge test (MCT) on patients with physician-diagnosed asthma on controller medications. A negative MCT has been generally interpreted as indicating that a patient with unexplained respiratory symptoms does not have asthma. However, we have observed that many potential participants evaluated for ACRC trials were disqualified because their $\mathrm{PC}_{20}$ (provocative dose of methacholine causing a $20 \%$ fall in $\mathrm{FEV}_{1}$ ) was greater than $16 \mathrm{mg} \mathrm{mL}^{-1}$ despite having a clinical history of physiciandiagnosed asthma receiving asthma treatment. Therefore, we investigated the ability of the MCT to differentiate non-asthmatics from asthmatic participants on controller treatment, with the hypothesis that use of high-potency inhaled steroids may have changed the sensitivity of the MCT. We observed that the sensitivity of MCT was $77 \%$ and the specificity was $96 \%$ (with threshold $\mathrm{PC}_{20}$ of $8 \mathrm{mg} \mathrm{mL}^{-1}$ ). The sensitivity was significantly lower for
Caucasians than for African-Americans (69 \% vs. $95 \%$, $p=0.015)$ and higher for those with atopy than for nonatopics ( $82 \%$ vs. $52 \%, p=0.005)$. Increasing the $\mathrm{PC}_{20}$ threshold from 8 to $16 \mathrm{mg} \mathrm{mL}^{-1}$ did not noticeably improve the performance characteristics of the test. The study indicated that the utility of the MCT to preclude diagnosis of asthma depends on racial and atopic characteristics [7].

\section{Adjunctive treatment trials: SIIVA, SARA, SARCA}

Treatment guidelines recommend preventative care, for example appropriate vaccinations, and treatment of comorbid conditions, for example gastroesophageal reflux (GER) and sinonasal disease, to improve asthma control. ALA-ACRC clinical trials have studied several questions related to these adjunctive treatments in asthma care. We will review network studies investigating the safety of influenza vaccination in asthma, and the effect of diagnosis and treatment of comorbid diseases on asthma control.

Is influenza vaccination safe for adults and children with asthma?

The study of inactivated influenza vaccination in asthmatics (SIIVA)

Although influenza vaccination is recommended for patients with asthma, historically both physicians and patients have been concerned about the possibility of vaccination-associated exacerbations of asthma. Retrospective studies and systematic reviews are indicative of conflicting results regarding the safety of influenza vaccination for children and adults with asthma $[18,19]$. The ACRC network's first study, SIIVA was a large simple trial designed to examine the safety of the influenza vaccination for people with asthma [1]. The trial was a randomized double-blind crossover placebo-controlled study that enrolled 712 children and 1,240 adults over a four-month period in 2000. We monitored symptoms, lung function, exacerbations, healthcare utilization, and missed school and work in the two-week period after each vaccination. We found no differences in the primary outcome of exacerbations within 14 days of injection. There was also no evidence of worsening of asthma in terms of symptoms or lung function. Other results from SIIVA included the evaluation of the effects of ICS therapy on the immune response to vaccination; the association between immunological markers of immune response and asthma exacerbation; an investigation of associations between nutrient intake and the signs and symptoms of asthma; and evaluation of predictors of poor asthma control [16, 20-23]. Results from this study showing no adverse effects of vaccination on asthma have helped to allay concerns about the risk 
of influenza vaccination and have helped physicians to confidently promote its safe use in patients with asthma.

Does treatment of acid reflux disease improve asthma control in adults and children with asthma?

The study acid reflux in asthma in adults (SARA) and the study of acid reflux and asthma in children (SARCA)

Gastroesophageal reflux (GER) and asthma are both common conditions and the prevalence of GER in asthmatics is high, estimated to be from $32 \%$ to $84 \%$. However, the contribution of GER to the signs and symptoms of asthma has been a subject of debate. Current guidelines recommend evaluating patients with poorly controlled asthma despite ICS treatment for GER and it is common practice for providers to empirically treat for possible GER with proton pump inhibitors (PPIs). Results of previous clinical trials assessing the effect on treatment of symptomatic GER on asthma have been conflicting [24-27]. In the SARA study, 412 adults with uncontrolled asthma despite use of moderate or high-dose ICS and minimum GER symptoms ( $<$ twice weekly) were randomized to either esomeprazole or placebo for 24 weeks over a three-year period (2004-2007) [6••]. Ambulatory pH monitoring was used to ascertain diagnosis of GER and the primary outcome was episodes of poor asthma control (EPACs). We found that despite a high prevalence of $\mathrm{pH}$ probe-diagnosed GER among participants $(40 \%)$, treatment with PPIs of those with infrequent or absent symptoms of GER, irrespective of $\mathrm{pH}$ probe results, did not affect asthma control (Fig. 2). An ancillary study looking at the effect of proximal vs. distal GER found that those with proximal reflux reported worse asthma and health-related quality of life in the absence of different asthma symptoms or different pulmonary function [28].

In a subsequent study of children conducted from 2007 to 2011, 306 children (ages 6-17, mean age 11) with asthma poorly-controlled on ICS were randomized to lansoprazole or placebo $[8 \bullet \cdot$. Among the 115 children who underwent ambulatory $\mathrm{pH}$ monitoring, $43 \%$ had GER, similar to the incidence in adults. Despite the frequency of GER in children, treatment with PPI was not associated with any difference in the primary outcome of asthma control, nor was it associated with differences in secondary outcomes, including measures of lung function, episodes of poor asthma control, symptoms, or quality of life. Similar negative results were obtained for the subgroup of children with GER by ambulatory $\mathrm{pH}$ probe. PPI treatment was associated with more upper respiratory tract infections, sore throat and bronchitis in children. Results of these studies suggest that investigation and treatment of GER in children and adults with asthma should be dictated by GER symptoms, not asthma symptoms, and that treatment of asymptomatic or minimally symptomatic GER does not affect asthma control. In children, these findings also add to other

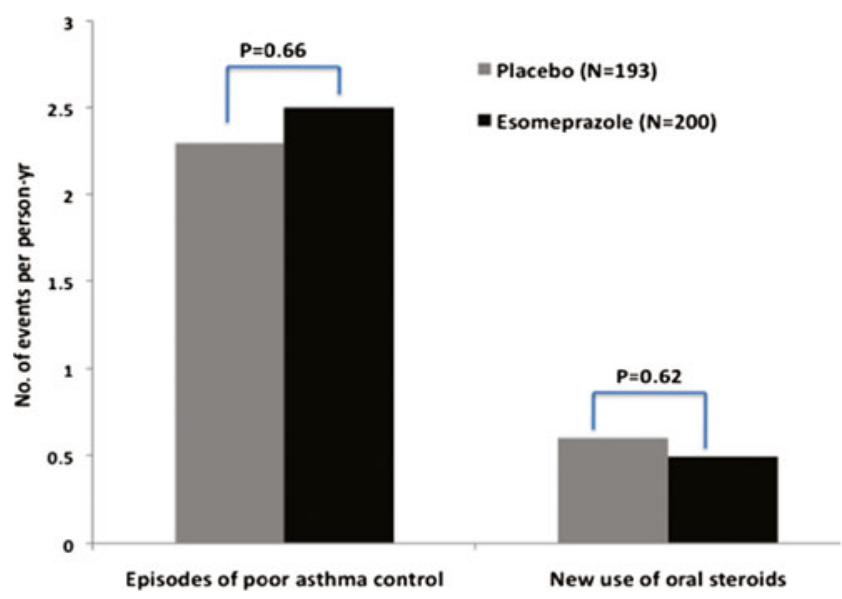

Fig. 2 Efficacy of esomeprazole for treatment of poorly controlled asthma (adapted from Ref. [6••]. Figure adapted from Table 3 of the reference describing primary outcome of the study. Episodes of poor asthma control were defined by a decrease of $30 \%$ or more in morning peak flow on two consecutive days, an urgent visit, and the need for course of oral prednisone for treatment of asthma. Reproduced with permission of the European Respiratory Society. European Respiratory Society Monograph 2011; 51 (Difficult-to-Treat Severe Asthma): 1627; DOI: $10.1183 / 1025448 x .10000610$

data suggesting possible links of PPI use with increased respiratory infections including pneumonia [29-33]. Because PPIs were used quite frequently for poorly-controlled asthma without GER symptoms, the potential cost savings to the healthcare system from SARA and SARCA is estimated to be billions of dollars.

\section{Ongoing and upcoming trials}

Will soy isoflavone supplements improve asthma not controlled by ICS alone?

\section{The study of soy isoflavones and asthma (SOYA)}

Recent increases in the prevalence and severity of asthma may be linked to decreased consumption of fresh fruit and vegetables and fresh fish in modern Western diets, but specific factors in diet that may affect asthma severity remain unclear. In an ancillary study linked to the SIIVA study, a standardized food survey was administered to assess the relationship between intake of different fruits, vegetables, antioxidants, fats, fiber, and micronutrients and asthma severity. The results were that low levels of the soy isoflavone genistein were associated with greater asthma severity as determined by lung function and exacerbation [22]. On the basis of these results and other pilot studies of genistein supplementation performed at the ACRC Chicago site, the SOYA study, a randomized doublemasked placebo-controlled trial to assess a soy isoflavone supplement as an adjunctive treatment for asthma not controlled on ICS alone, was conducted with joint support of 
ALA and NIH/NHLBI funding. SOYA has completed recruitment and results will be reported within the forthcoming year.

Does treatment of sinonasal disease with nasal steroids improve asthma control?

\section{The study of asthma and nasal steroids (STAN)}

Chronic sinonasal disease is common in patients with asthma, and has been associated with poor asthma control $[15,16]$. Animal and human studies suggest a link between upper airway processes and lower airway dysfunction [34]. Over $30 \%$ of participants in ACRC clinical trials have reported symptoms of sinonasal disease. It is widely believed in the medical community that treatment of sinonasal disease improves asthma control, but this has not been clearly demonstrated in prospective clinical trials. In particular, it is not clear whether one of the crucial treatments for sinonasal disease, nasal steroids, results in improvement of asthma control. The network's 9th study, STAN, is supported by a grant from NIH-NHLBI. The objective of the trial is to determine whether treatment of sinonasal disease with nasal steroids results in improved asthma control. In this study, patients with uncontrolled asthma and sinonasal disease as indicated by the score on the SNQ (developed and validated as described earlier in the SIRNA study) were randomized to nasal steroid or placebo. The primary outcome measured is asthma controlled as measured by the asthma control test. This study is currently ongoing and results will be reported in 2013.

How do you reduce asthma therapy for patients with asthma well controlled on moderate dose combination inhaled corticosteroids and long-acting beta agonists (ICS/LABA)?

\section{Long acting beta agonist step-down study (LASST)}

Current asthma guidelines recommend stepping down therapy when asthma is controlled for at least three months. When mild asthma is controlled, ICS can often be reduced by $50 \%$, but reducing therapy is less successful with rapid ICS tapering and for moderate-to-severe disease [35-38]. The optimum approach to reducing treatment for patients with asthma treated with ICS/LABA is not clear and is a key question for practitioners caring for patients with moderate to severe persistent asthma, especially in the light of the ongoing controversy regarding LABA safety. The ALA-ACRC recently embarked on a 56-week multi-center, prospective, randomized, three-arm parallel group comparative effectiveness trial comparing three approaches to managing patients with wellcontrolled asthma on combination ICS/LABA. In this study, adults and children on moderate dose ICS/LABA were randomized to reduction of ICS dose and continuation of LABA, continuation of same dose of ICS and discontinuation of
LABA, or continuation of stable dose ICS/LABA. The primary outcome is treatment failure, a composite score based on symptoms, lung function, and exacerbations requiring oral corticosteroids. The LASST trial was designed with clinically relevant primary outcomes and longer-term follow-up after reduction of asthma treatment to provide definitive evidence to guide clinicians on how to safely minimize medication in patients with moderate to severe asthma.

Does treatment of patients with uncontrolled asthma with continuous positive airway pressure (CPAP) but without significant sleep apnea improve airway hyperreactivity?

\section{The effect of positive airway pressure on reducing airway} reactivity in patients with asthma (CPAP)

Alternative, non-pharmacological, approaches to treatment of asthma could reduce the morbidity and costs associated with asthma treatment. One of the cardinal features of asthma is bronchial hyperreactivity, the tendency of airways to constrict in response to specific stimuli. In experimental models, airway hyperreactivity can be induced by prevention of stretching of airway smooth muscle and reduced airway tone may be associated with hyperreactivity [39, 40]. During sleep, there is loss of the ability to take a deep inspiration that also may contribute to a loss of protective airway dilation and contribute to nocturnal asthma symptoms common in uncontrolled asthma [41]. Several animal studies and small preliminary human studies of the shortterm use of CPAP suggest that its use may reduce bronchial hyperreactivity in asthma. [42-44]. These preliminary data suggest a need for further evaluation of CPAP as a treatment for asthma. In a recently launched ACRC study, patients with asthma will be randomized to one of two levels (5 or $10 \mathrm{~cm} \mathrm{H}_{2} \mathrm{O}$ ) of CPAP at night, and another group will receive "sham" CPAP. The study will evaluate whether treatment for 12 weeks with nocturnal CPAP will reduce airway hyperreactivity as measured by methacholine challenge for patients with asthma. It will also assess whether nocturnal CPAP treatment will improve asthma symptoms and will be tolerated by patients with asthma. The results of the study will determine whether further evaluation of CPAP as an asthma treatment is warranted.

\section{Why has the ACRC been successful?}

The success the ALA-ACRC network is a result of several factors. First and foremost is the willingness of the ALA to envisage and support the overall mission of the network while enabling the investigators to develop and champion the individual studies. Because many trials need as long as 
5-8 years from study concept to completion, the long-term core support from ALA of a large number of centers provides the stable funding stream that is essential for recruitment of the large numbers of patients needed to definitively establish whether some widely used asthma treatments are beneficial or ineffective. Second, the ACRC is a model of how collaborative efforts of the non-profit ALA and the government-supported NHLBI joined by support from the pharmaceutical industry can efficiently and effectively deliver high-quality clinical research for a targeted disease. Although the funding models may differ from trial to trial, the basic approach is that the ALA provides core funds for support of the investigators and key clinical staff. The NIHNHLBI provides scientific merit review and support for costs of conducting the trials under a cooperative agreement mechanism. Private industry provides support by contributing drugs and devices either at no cost or at discount. The Data Coordinating Center is jointly supported by ALA funding as well as NIH-NHLBI funding under cooperative agreements and grants. Third, ACRC have been able to manage an active pipeline of ideas for new studies and maintain our focus on comparative effectiveness trials, i.e., those that provide direct comparisons of treatment strategies in diverse groups of patients. Wide distribution of the centers across the nation enabled ACRC to engage diverse group of patients with asthma, including minorities. Furthermore, engaging the unique intellectual capital and scientific resources available from each of the network centers has been a key component of the success thus far. Finally, the network has benefited by encouraging mentorship of younger investigators who have contributed significantly to the productivity of the group.

\section{Conclusion}

ALA-ACRC is one of the largest asthma clinical networks in the United States and has successfully completed eight clinical studies in asthma since 1999. The results from these studies have had a direct effect on the clinical management of patients with asthma. Two studies are currently approaching completion and two studies are currently starting that we expect to answer important questions in asthma care and hopefully have a significant effect on the direct day-to-day management of patients with asthma.

Acknowledgements We would like to acknowledge current and former ACRC centers

\section{Current ACRC centers}

Baylor College of Medicine, Houston, TX, USA; Duke University Medical Center, Durham, NC, USA; The Illinois Consortium, Chicago, IL, USA; Hofstra University School of Medicine (formerly Long Island Jewish Health System), New Hyde Park, NY, USA; Louisiana State University Health Sciences Center, Ernest N. Morial Asthma,
Allergy, and Respiratory Disease Center, New Orleans, LA, USA; Nemours Children's Clinic, Jacksonville, FL, USA; National Jewish Medical and Research Center, Denver, CO, USA; Northern New England Consortium at the University of Vermont, VT, USA; Colchester Columbia University-New York University Consortium, New York, NY, USA; Maria Fareri Children's Hospital at Westchester Medical Center and New York Medical College, Valhalla, NY, USA; The Ohio State University/Columbus Children's Hospital, Columbus, $\mathrm{OH}$, USA; St. Louis Asthma Clinical Research Center: Washington University, St. Louis University, Saint Louis, MO, USA; St Vincent Hospital and Health Care Center (not starting until Sept 2012), Indianapolis, IN, USA; University of Arizona, Tucson, AZ, USA; University of California, San Diego, CA, USA; University of Missouri - Kansas City School of Medicine, Kansas City, MO, USA; University of Miami, Miami -University of South Florida, Tampa, FL, USA; University of Virginia, Charlottesville, VA, USA; Johns Hopkins University Bloomberg School of Public Health; American Lung Association; Chairman's Office - University of Alabama at Birmingham

\section{Former ACRC centers}

Emory University School of Medicine, Atlanta, GA, University of Minnesota, Minneapolis, MN, USA; Indiana University Asthma Clinical Research Center, Indianapolis, IN, USA; University of Pennsylvania, Philadelphia, PA, USA; Jefferson Medical College, Philadelphia, PA, USA; Respiratory Hospital, Winnipeg, Manitoba, Canada - former Chair, N. Anthonisen

We also gratefully acknowledge our ongoing core support from the America Lung Association, NIH/NHLBI support including R01HL073494 (TAPE), 5U01HL072968 (SARA), R01 HL08798701A2 (SOYA) R01 HL0088367-01A2 (SOYA), RO1 HL080433 (SARCA), R01 HL080450 (SARCA), R01 HL089464-01A2 (STAN), R01 HL00895101-01A2 (STAN), U01 HL 108730 (CPAP), and our industry partners, Merck, GlaxoSmithKline, Schering Plough, AstraZeneca, Archer Daniels Midland Company, Tap Pharmaceuticals, and ResMed

Disclosure No potential conflicts of interest relevant to this article were reported.

\section{References}

Papers of particular interest, published recently, have been highlighted as:

- Of importance

•. Of major importance

1. The safety of inactivated influenza vaccine in adults and children with asthma. N Engl J Med. 2001 Nov 22;345(21):1529-36

2. Clinical trial of low-dose theophylline and montelukast in patients with poorly controlled asthma. Am J Respir Crit Care Med. 2007 Feb 1;175(3):235-42

3. - Peters SP, Anthonisen N, Castro M, et al. Randomized comparison of strategies for reducing treatment in mild persistent asthma. N Engl J Med. 2007;356(20):2027-39. Trial showed alternative step-down treatments for mild asthma.

4. Dixon AE, Sugar EA, Zinreich SJ, et al. Criteria to screen for chronic sinonasal disease. Chest. 2009;136(5):1324-32.

5. Wise RA, Bartlett SJ, Brown ED, et al. Randomized trial of the effect of drug presentation on asthma outcomes: the American Lung Association Asthma Clinical Research Centers. J Allergy Clin Immunol. 2009;124(3):436-44. 44e1-8.

6. •- Mastronarde JG, Anthonisen NR, Castro M, et al. Efficacy of esomeprazole for treatment of poorly controlled asthma. N Engl J 
Med. 2009;360(15):1487-99. Trial showed that PPI is not effective for asthma control in asymptomatic adults.

7. Sumino K, Sugar EA, Irvin CG, et al. Methacholine challenge test: diagnostic characteristics in asthmatic patients receiving controller medications. J Allergy Clin Immunol. 2012;130(1):69-75 e6.

8. •- Holbrook JT, Wise RA, Gold BD, et al. Lansoprazole for children with poorly controlled asthma: a randomized controlled trial. JAMA. 2012;307(4):373-81. Trial showed that PPI is not effective for asthma control in asymptomatic children.

9. Mastronarde JG, Wise RA, Shade DM, et al. Sleep quality in asthma: results of a large prospective clinical trial. J Asthma. 2008;45(3):183-9.

10. Poon AH, Tantisira KG, Litonjua AA, et al. Association of corticotropin-releasing hormone receptor-2 genetic variants with acute bronchodilator response in asthma. Pharmacogenet Genomics. 2008;18(5):373-82.

11. Lima JJ, Zhang S, Grant A, et al. Influence of leukotriene pathway polymorphisms on response to montelukast in asthma. Am J Respir Crit Care Med. 2006;173(4):379-85.

12. Plaschke PP, Janson C, Norrman E, et al. Onset and remission of allergic rhinitis and asthma and the relationship with atopic sensitization and smoking. Am J Respir Crit Care Med. 2000;162(3 Pt 1):920-4.

13. Settipane RJ, Hagy GW, Settipane GA. Long-term risk factors for developing asthma and allergic rhinitis: a 23-year follow-up study of college students. Allergy Proc. 1994;15(1):21-5.

14. Ferrante ME, Quatela MM, Corbo GM, et al. Prevalence of sinusitis in young asthmatics and its relation to bronchial asthma. Mil Med. 1998;163(3):180-3.

15. ten Brinke A, Sterk PJ, Masclee AA, et al. Risk factors of frequent exacerbations in difficult-to-treat asthma. Eur Respir J. 2005;26 (5):812-8.

16. Dixon AE, Kaminsky DA, Holbrook JT, et al. Allergic rhinitis and sinusitis in asthma: differential effects on symptoms and pulmonary function. Chest. 2006;130(2):429-35.

17. Graham B, Regehr G, Wright JG. Delphi as a method to establish consensus for diagnostic criteria. J Clin Epidemiol. 2003;56 (12):1150-6.

18. Kramarz P, DeStefano F, Gargiullo PM, et al. Does influenza vaccination exacerbate asthma? Analysis of a large cohort of children with asthma. Vaccine Safety Datalink Team. Arch Fam Med. 2000;9(7):617-23.

19. Kramarz P, DeStefano F, Gargiullo PM, et al. Influenza vaccination in children with asthma in health maintenance organizations. Vaccine Safety Datalink Team. Vaccine. 2000;18(21):2288-94.

20. Miller RL, Cheng M, DiMango EA, et al. T-cell responses and hypersensitivity to influenza and egg antigens among adults with asthma immunized with the influenza vaccine. J Allergy Clin Immunol. 2003;112(3):606-8.

21. Hanania NA, Sockrider M, Castro M, et al. Immune response to influenza vaccination in children and adults with asthma: effect of corticosteroid therapy. J Allergy Clin Immunol. 2004;113(4):717-24.

22. Smith LJ, Holbrook JT, Wise R, et al. Dietary intake of soy genistein is associated with lung function in patients with asthma. J Asthma. 2004;41(8):833-43.

23. McCoy K, Shade DM, Irvin CG, et al. Predicting episodes of poor asthma control in treated patients with asthma. J Allergy Clin Immunol. 2006;118(6):1226-33.

24. Coughlan JL, Gibson PG, Henry RL. Medical treatment for reflux oesophagitis does not consistently improve asthma control: a systematic review. Thorax. 2001;56(3):198-204.

25. Donnellan C, Sharma N, Preston C, Moayyedi P. Medical treatments for the maintenance therapy of reflux oesophagitis and endoscopic negative reflux disease. Cochrane Database Syst Rev. 2005(2):CD003245
26. Kiljander TO, Harding SM, Field SK, et al. Effects of esomeprazole $40 \mathrm{mg}$ twice daily on asthma: a randomized placebocontrolled trial. Am J Respir Crit Care Med. 2006;173(10):1091-7.

27. Littner MR, Leung FW, Ballard ED, et al. Effects of 24 weeks of lansoprazole therapy on asthma symptoms, exacerbations, quality of life, and pulmonary function in adult asthmatic patients with acid reflux symptoms. Chest. 2005;128(3):112835.

28. DiMango E, Holbrook JT, Simpson E, et al. Effects of asymptomatic proximal and distal gastroesophageal reflux on asthma severity. Am J Respir Crit Care Med. 2009;180(9):809-16.

29. Orenstein SR, Hassall E, Furmaga-Jablonska W, et al. Multicenter, double-blind, randomized, placebo-controlled trial assessing the efficacy and safety of proton pump inhibitor lansoprazole in infants with symptoms of gastroesophageal reflux disease. J Pediatr. 2009;154(4):514-20 e4.

30. Meijvis SC, Cornips MC, Voorn GP, et al. Microbial evaluation of proton-pump inhibitors and the risk of pneumonia. Eur Respir J. 2011;38(5):1165-72.

31. Eom CS, Jeon CY, Lim JW, et al. Use of acid-suppressive drugs and risk of pneumonia: a systematic review and meta-analysis. CMAJ. 2011;183(3):310-9.

32. Laheij RJ, Sturkenboom MC, Hassing RJ, et al. Risk of community-acquired pneumonia and use of gastric acidsuppressive drugs. JAMA. 2004;292(16):1955-60.

33. Canani RB, Cirillo P, Roggero P, et al. Therapy with gastric acidity inhibitors increases the risk of acute gastroenteritis and community-acquired pneumonia in children. Pediatrics. 2006;117 (5):e817-20.

34. Corren J, Adinoff AD, Irvin CG. Changes in bronchial responsiveness following nasal provocation with allergen. J Allergy Clin Immunol. 1992;89(2):611-8.

35. Haahtela $T$, Jarvinen $M$, Kava $T$, et al. Effects of reducing or discontinuing inhaled budesonide in patients with mild asthma. $\mathrm{N}$ Engl J Med. 1994;331(11):700-5.

36. Juniper EF, Kline PA, Vanzieleghem MA, Hargreave FE. Reduction of budesonide after a year of increased use: a randomized controlled trial to evaluate whether improvements in airway responsiveness and clinical asthma are maintained. J Allergy Clin Immunol. 1991;87(2):483-9.

37. Hawkins G, McMahon AD, Twaddle S, et al. Stepping down inhaled corticosteroids in asthma: randomised controlled trial. BMJ. 2003;326(7399):1115.

38. Lemanske Jr RF, Sorkness CA, Mauger EA, et al. Inhaled corticosteroid reduction and elimination in patients with persistent asthma receiving salmeterol: a randomized controlled trial. JAMA. 2001;285(20):2594-603.

39. Xue Z, Zhang L, Liu Y, et al. Chronic inflation of ferret lungs with CPAP reduces airway smooth muscle contractility in vivo and in vitro. J Appl Physiol. 2008;104(3):610-5.

40. Xue Z, Zhang L, Ramchandani R, et al. Respiratory system responsiveness in rabbits in vivo is reduced by prolonged continuous positive airway pressure. J Appl Physiol. 2005;99(2):677-82.

41. Irvin CG, Pak J, Martin RJ. Airway-parenchyma uncoupling in nocturnal asthma. Am J Respir Crit Care Med. 2000;161(1):50-6.

42. Ciftci TU, Ciftci B, Guven SF, et al. Effect of nasal continuous positive airway pressure in uncontrolled nocturnal asthmatic patients with obstructive sleep apnea syndrome. Respir Med. 2005;99(5):529-34.

43. Lafond C, Series F, Lemiere C. Impact of CPAP on asthmatic patients with obstructive sleep apnoea. Eur Respir J. 2007;29(2):307-11.

44. Lin HC, Wang CH, Yang CT, et al. Effect of nasal continuous positive airway pressure on methacholine-induced bronchoconstriction. Respir Med. 1995;89(2):121-8. 